\title{
Choice and Application of Green Materials in Product
}

\author{
Wei Chen \\ Jiangsu Open University, Nanjing, China
}

\begin{abstract}
Based on the basic properties of the green material itself, environmental adaptability and feeling of comfort, analyzes that green materials should follow the basic principles, that are the use of good workability, good processing manufacturability, best economy, good aesthetics, non-toxic harmless and low energy consumption, easy to recycle and innovative; puts forward the relationship between the green materials and the three elements of product design that the green material is the an important factor in the material technical conditions, is a necessary condition realizing its use function, and is the material base of its moulding image. And some examples are given to illustrate the application of green materials in product design.
\end{abstract}

Keywords-product; green materials; nature materials; choise

\section{INTRODUCTION}

The primary task of product design is to design some new products meeting the demand of users, adapting to the market competition, and make these new products quickly occupy the market.

Design can stimulate the evolution and development of human society with strong power at any time. From the date of birth, the design always reflects social and human needs, focus on a pressing matter of the moment of human society, solves a major subject in the in the field of human production and life.

Now, people focus on the environmental pollution problem, this is the top priority of human society, it is a huge problem affecting the human existence. Therefore, to pay attention to environmental protection consciousness, to pay attention to the choise and application of green materials, is the most important problem that people have to think about in the design, also is an important means of product innovation.

\section{ChOice Of Green Materials In PRODUCt}

\section{A. The Performance of the Green Materials}

The materials with ecological environment in harmony in the extraction of raw materials, product manufacturing use and recycling, and waste disposal etc., and beneficial to human health is called the green materials. It should have purification absorption function and promote human healthy function [1].

As a result, the green material must have basic performances of good practicability and economy consistent with traditional materials, also should have good environmental adaptability, and all kinds of comfort feeling.

Therefore, the basic properties of the material, the material environment adaptability and the material feeling comfort constitute the performance of the green material, listing in Table I.
TABLE I. THE PERFORMANCE OF THE GREEN MATERIAL

\begin{tabular}{|c|c|c|}
\hline $\begin{array}{c}\text { Green material } \\
\text { properties }\end{array}$ & Descriptions & For example, \\
\hline $\begin{array}{c}\text { The basic } \\
\text { properties of itself }\end{array}$ & $\begin{array}{c}\text { Mechanical properties, } \\
\text { physical properties, } \\
\text { chemical properties, etc }\end{array}$ & $\begin{array}{c}\text { Strength, stiffness, } \\
\text { stability, fatigue } \\
\text { characteristics, } \\
\text { balance, impact } \\
\text { resistance, corrosion } \\
\text { resistance, etc. }\end{array}$ \\
\hline environment & $\begin{array}{c}\text { Harmless, recycling of } \\
\text { renewable, ease of } \\
\text { disposal, low energy } \\
\text { consumption of } \\
\text { manufacturing, etc }\end{array}$ & $\begin{array}{c}\text { Non-toxic, recycling, } \\
\text { climate adaptation, } \\
\text { temperature } \\
\text { adaptation, moisture } \\
\text { proof, corrosion } \\
\text { resistant, low energy } \\
\text { consumption. }\end{array}$ \\
\hline material feeling & Visual feeling, touch \\
comfort & feeling, taste feeling, \\
prevent noise & $\begin{array}{c}\text { harmonious pleasant } \\
\text { color, harmonious } \\
\text { texture, quiet shape }\end{array}$ \\
\hline
\end{tabular}

B. The Principle of Choice on the Green Materials

The choice of the green materials is an important starting point of product design. Choosing whether or not the green materials is suitable will directly affect the product design itself [2]. The kinds of green materials are very many, each material has its own features, and new materials are constantly emerging.

As a product designer, he should both give play to the material characteristics and pay attention to material minimum pollution to the environment according to the principle of choice on the green materials, at the same time, he pay attention to product design moulding style and features. Through the use of the material, the designed products are fully expressed to the aesthetics of the material and texture features.

Green material should follow the following basic principles.

1) The use of good workability: In the choice of materials, the most basic condition is that the performance of the material must meet the product function and its use requirement.

The use workability of materials includes their mechanical properties, physical properties, chemical properties, etc. The product function, its service life, its structure, its use security demands, working environment adaptability, etc. are also considered

2) The good processing manufacturability: Materials can become a product only through forming process. The used material must have the performance of easy to processing and manufacturing, its processing technology must meet the requirements of its forming, its surface treatment etc.. 
3) The best economy: In the choice of materials, the material economy is an important principle, it directly related to the manufacturers and consumers. Therefore, the choice of materials should help enterprises to reduce the production costs, obtain the biggest profit, and enable consumers to obtain satisfaction.

The best economy is that the material not only refers to relatively cheap of its price, but should be in the entire life cycle of the product, considering the impact of material comprehensively, such as its price, its difficulty of the processing technology, its cost of the product recycling, etc.

4) The good aesthetics: The beauty products will attract the public consumption. The beauty of product is mainly reflected in two aspects, one is external "formal beauty ", another is the inner "technical beauty"[4]. The beauty of the material, namely material beauty is one of the important technical beauty, is embodied by human touch and vision. Therefore, in the choice of materials, the designers should consider human touch feeling and visual feeling for materials, to achieve real beauty products.

5) The non-toxic harmless: Product is for people to use, therefore, in the choice of materials, Must consider, in the process of the production and use, that the materials is harmless to human body and environment.

6) Low energy consumption: The material energy consumption is very different in the process of refining and processing. In the green design should give priority to materials which are low energy consumption in the process of manufacturing. To reduce the volume and weight of the product, that is, using less lighter materials to make products, also can effectively reduce energy consumption and cost.

7) Easy to recycle and reuse: In the process of product design, should choose those materials which are easy to recycle and reuse. Generally speaking, the recycling of metal materials is better, non-metal recycling is poorer. thermoplastic materials can be reused in plastics, and the decomposition and recycling of thermosetting plastics are more difficult. A single material is easy to recycle, and the recycling of compound and mixed material is more difficult.

8) The innovation: Only innovation can gain market, only innovation can obtain intellectual property rights. With the rapid development of science and technology, new materials constantly emerging, this provides a strong material base for product innovation.

Based on the new material, on the one hand, the existing products can be realized through the use of new materials to achieve new forms, new composition structure, and new technological ways. so as to create a new design language for the original products, to give new connotation and quality; On the other hand, using the new materials can be used to develop new products, This is a completely innovative design.

C. The Relationship between Green Materials and the Three Elements of Product Design

Products, as an objective entity, it contains three elements that are the use function, moulding image and material technical conditions [5]. The use function is the use value of a product, the material technical conditions are the material basis for the realization of the product, and the moulding image is the active use of the material basis, to give the use of functions to specific artistic expression.

Product material is important factor in the material technical condition; The realization of the use function of products is dependent on the material, it is a necessary condition realizing the use function; The moulding image of product also cannot leave the material, it is the material basis for it.

The relationship between green materials and the three elements of product design is as shown in figure I.

1) The green material is an important factor in material technical conditions: Product's material technical conditions include green materials, processing technology, processing equipment, etc. They are fundamental conditions to realize product's use function and moulding image, are the intermediate factors that constitute the use function and moulding image of products. Among them, the green material is an important factor in the product's material technical conditions.

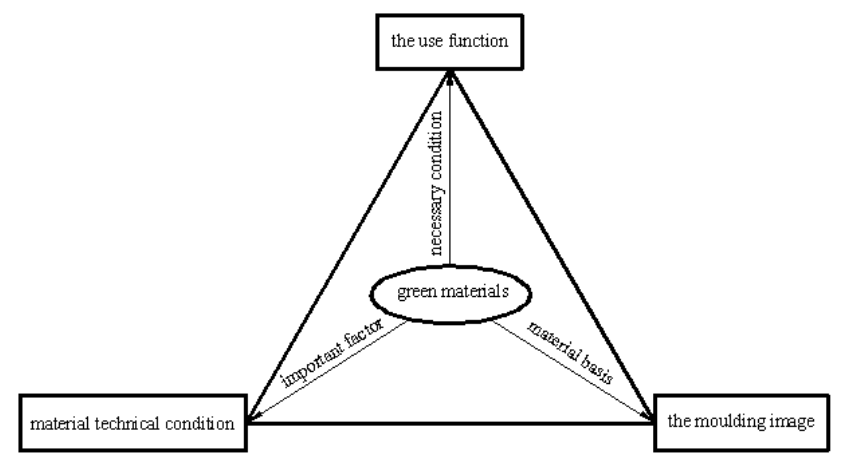

FIGURE I. THE RELATIONSHIP BETWEEN GREEN MATERIALS AND THE THREE ELEMENTS OF PRODUCT DESIGN

2) The green material is a necessary condition realizing the use function: The use function of modern products has rich connotation, which includes two aspects of practical function and mental function. Practical function includes physical function and physiological function; Mental function include psychological function and social function. Product's performance, function and the structure belong to the physical features; Product's convenience to use, security to use, pleasant to use belong to the physiological function; Product moulding, color, texture, etc. belong to the psychological function, to give person a feeling of pleasure; The personal social status, interest and value which product shows or symbolizes belong to the social function.

Without green materials is not to realize the product's practical function and mental function, is also not to win the market. Therefore, green material is a necessary condition realizing the use function. 
3) The green material is the material base of product moulding image: Product moulding image is represented by material configuration and material texture The material configuration can combine into the constantly changing product form, the material texture can enrich the beauty of human vision and touch. They are the material basis for the product moulding image.

Different materials can form a certain product structure by different processing methods, connection and combination, this is the configuration. Therefore, the configuration is an important factor to form product form, even the most simple products, also has a certain configuration.

The material texture refers to having surface texture by choosing the natural materials or obtaining the artificial processing. According to human perception, the texture can be divided into tactile texture and visual texture.

Tactile texture refers to the feeling of comfort or disgust by the contact of the human body. Such as, the fine ceramic, soft satin and valuable fur give a person fine, soft, smooth, tender, comfortable feeling; The rough wall, the wet paint, rusty implements etc. give a person coarse, acerbity, disgust feeling.

Visual texture is based on the accumulation of tactile experience, for already familiar with the organization of the material surface, only by sight can judge its texture without direct contact. For example, iron and steel products give a person a strong heavy feeling, aluminum products give a person a light and gorgeous feeling, plastic products give a person a light and gentle feeling, wooden products give a person natural and guileless feeling.

\section{The ApPlication Of GREen Materials In Product}

A. PP is the Choice of the Internal Material in Household Automatic Dishwasher

A household automatic dishwasher, as shown in figure 2 [7], is a kind of a household kitchen appliance which can replace the manual washing the bowl, plate, dish, cup, spoon, chopsticks, knives, forks, pan, shovel, cooking utensils ect. to reduce the human labor intensity, improve work efficiency, and promote clean sanitation.

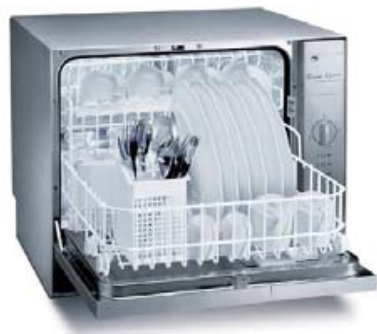

FIGURE II. A HOUSEHOLD AUTOMATIC DISHWASHER

A dishwasher mainly used ultrasonic cleaning. Detergent has the effect of auxiliary, cleaning effect is remarkable and health[8].

Due to the dishwasher washing bowl is for people to use, so the choice of the dishwasher internal material must be green materials.
The dishwasher internal materials commonly are ABS, PP, PC, stainless steel. In order to choose the best material from these alternative materials, the specific approaches are as follows [9]:

1) The stress analysis and drop analysis of $A B S, P P, P C$, stainless steel: Under the conditions that the material yield stress is not exceeded, and the force demand is satisfied, the priority order of the deformation of material is stainless steel $>$ PC $>$ PP $>$ ABS.

Under the conditions that the maximum stress is less than the yield stress, no plastic deformation occurs, the performance priority order under impact load is PP > ABS $>$ PC > stainless steel.

2)The heat transfer performance analysis of $A B S, P P, P C$, stainless steel: The dishwasher will be heated to the washing water in the process of washing the dishes, so the lower part of the dishwasher inside is in hot water. In general, a time to wash the dishes is between 90 to 120 minutes, therefore, the heat loss of the dishwasher should not be neglected. Through calculation shows that the heat loss of these materials, from large to small, is stainless steel $>\quad \mathrm{PC}>\mathrm{ABS}>\mathrm{PP}$.

3)The material cost analysis of the ABS, $P P, P C$, stainless steel: Only consider the cost of raw materials, according to the market price, the cost of these materials, from high to low, is as follows: stainless steel $>$ PC $>$ ABS $>$ PP.

4)The environmental performance analysis of the ABS, $P P$, $P C$, stainless steel: The environmental factors include the consumption, pollution(temperature effect and the depletion of the ozone layer, human toxicity, ecological toxicity, acidification, etc.) and damage of material and energy. And analysis shows that during process of materials production, the index for environmental impact is stainless steel > PC> ABS > PP; During materials processing, the index for environmental impact is $\mathrm{PC}>\mathrm{ABS}>\mathrm{PP}>$ stainless steel.

5)Overall evaluation of the $A B S, P P, P C$, stainless steel: On the above analysis, that the experts give the weight of evaluation, from big to small, is the heat transfer performance $>$ the environmental impact during process of materials production $>$ the cost of materials $>$ mechanical properties $>$ drop performance $>$ the environmental impact during materials processing.

6)The choice of the ABS, PP, PC, stainless steel: At present, although the internal materials of the most dishwashers are stainless steel materials, through the comprehensive evaluation results of performance, the PP material is the best material for the comprehensive performance, so it is recommended to choose PP material for the inside material of a automatic dishwasher.

\section{B. The Application of Bamboo in the Automobile Moulding}

The material in nature is a natural green material. No matter from which link, the material in nature fully conforms to the general basic principles which green materials do it. 
After a certain process, natural material has high strength, natural surface texture, plain and clear. In product design, if natural materials are chose, the pollution to the environment can greatly reduced, to make people more close to the nature, and nature material is the inexhaustible renewable resources in the nature.

At present, a popular natural material is bamboo [10]. Due to the fast growth of bamboo, its texture hard and soft, is considered to be a very good environmental protection material. Based on this understanding, a bamboo has begun to be used in the industrial products more and more, and gradually replace the steel and plastic.

At the Geneva auto show in 2011, show a bamboo concept car [11], as shown in figure 3. As the term suggests, the material of concept car is composed of renewable bamboo, that is, the material of the car floor and interior cover is made of bamboo. The moulding concept is to arouse people's memories of the 1970s.
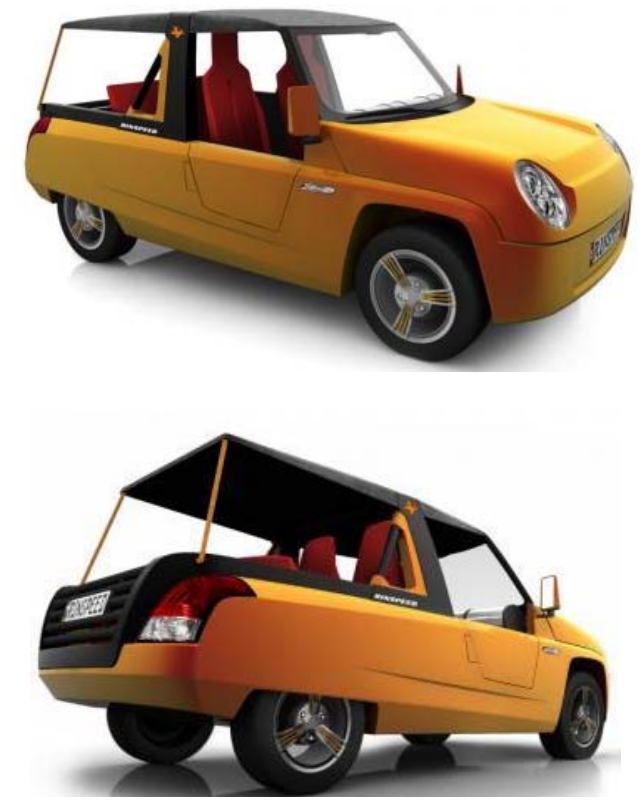

FIGURE III

THE APPLICATION OF BAMBOO IN THE AUTOMOBILE MOULDING

As a result of the bamboo is easy to get, so the cost of the car will be very low. And in the process of the growth of the raw materials of the car, the emissions of carbon dioxide is negative. About power, the car will take electric power in the future, so from the material to the power will realize completely pollution-free

The car of the future will be a what kind of development direction? maybe the bamboo concept car is one of developing direction.

\section{CONCLUSION}

The green materials which are chose from a large number of alternative materials are to meet the requirements of product function, to meet consumer demands, to adapt to the market needs. That is to say, the choice of product materials should comprehensively consider the material basic properties of itself, environment adaptability and feeling comfort.

\section{ACKNOWLEDGMENTS}

This research was supported by project on science and technology innovation team about application of the internet of things technology.

\section{REFERENCES}

[1] Xiu-feng Zhang: Green design about mechanical and electrical product and engineering example. Chemical industry publishing house, 2015.

[2] Jing-yuan Yao: Product material and design. National defence industry publishing house, 2015.

[3] Cheng-qi Xue, etc. Foundation of industrial design. Southeast University publishing house, 2012.

[4] Xiao-yuan Li, Shu-jie Dong: Industrial design creativity unlock. Tsinghua University publishing house, 2015.

[5] Zhen-bang Chen: Moulding aesthetic of agricultural machinery. Mechanical industry publishing house, 1986.

[6] Wei Chen: The research and application of green design. Development and innovation of mechanical and electrical pro duct 2007, 105 (4) : 33-34

[7] Anonymity: Let kitchen life better. [EB/OL].http: //www.525j.com.cn/zhishi/zxzs/20140125152896204.shtml

[8] Anonymity: Is dishwasher safe to use? [EB/OL].http://www. pchouse. com. cn / baike/shenghuo/851/

[9] Zhi-feng Liu etc. :Materials selection for dishwasher tubs based on

[10] Green design. Journal of Hefei University of technology, 2011 (10) : $1446 \sim 1451$

[11] Peng Ye: Natural materials research in the modern product design

[12] [EB/OL] http://www. doc88.com/p-4843965812706 HTML

[13] Jia-gang Huang: Zero pollution, Make bamboo concept car . [EB/OL] http://auto.sohu.com/20101202 / n278047971. SHTML 